\title{
REFLEXÕES SOBRE O LUGAR DA ESCOLA NA FORMAÇÃO DE PROFESSORES DE EDUCAÇÃ̃O FÍSICA
}

\author{
Tamara Suellen Dudeck? \\ Evando Carlos Moreira? \\ José Pereira de Melo 3
}

\begin{abstract}
RESUMO
Propomos neste ensaio refletir sobre o lugar da escola na formação dos professores de Educação Física, partindo do princípio de que sem conhecer a escola, o cotidiano escolar, não há possibilidade de compreender de suas reais necessidades. Presupomos que a escola ocupa pouco espaço na formação de professores de Educação Física, mas percebem-se mudanças substanciais nas leis e na oferta de projetos e programas que permitem articulação entre as agências formadoras e a escola para inserir os licenciandos em Educação Física no contexto escolar desde os primeiros períodos do curso, realidade que possibilita um processo formativo vivencial no próprio contexto escolar.
\end{abstract}

Palavras-chave: Formação de Professores. Educação Física. Escola.

1 Mestre em Educação Física. Professora da Rede Municipal de Ensino de Cuiabá. Cuiabá/Mato Grosso, Brasil. E-mail: tamara-suellen@hotmail.com

2 Doutor em Educação Física. Professor da Universidade Federal de Mato Grosso (UFMT). Cuiabá/Mato Grosso, Brasil. E-mail: ecmmoreira@uol.com.br

3 Doutor em Educação Física. Professor da Universidade Federal do Rio Grande do Norte (UFRN). Natal/Rio Grande do Norte, Brasil. E-mail: jose.pereira.melo@uol.com.br 


\title{
REFLECTIONS ABOUT THE ROLE OF SCHOOL IN PREPARATION OF TEACHERS OF PHYSICAL EDUCATION
}

\begin{abstract}
It is proposed in this paper reflect on the role of school in the preparation of Physical Education teachers, assuming that there isn't possibility of comprehension their real needs without knowledge about the school and the school routine. We assume that the school should have more room in the preparation of Physical Education teachers, but are perceived substantial changes in the laws and the demand projects and programs that allow an articulation between the educational teachers institutions and schools to insert students physical education in the school context from the earliest periods of the course, a reality that enables an experiential educational within the school context.
\end{abstract}

Keywords: Teacher Formation. Physical Education. School.

\section{REFLEXIONES SOBRE EL PAPEL DE LA ESCUELA EN LA PREPARACIÓN DE LOS PROFESORES DE EDUCACIÓN FÍSICA}

\section{RESUMEN}

Se propone en este trabajo reflexionar sobre el lugar de la escuela en la preparación de los profesores de educación física, en el supuesto de que no hay posibilidad de comprensión de sus necesidades reales sin el conocimiento sobre la escuela y la rutina escolar. Suponemos que la escuela debe tener más espacio en la preparación de los profesores de Educación Física, pero se perciben cambios importantes en las leyes y la oferta los proyectos y programas de abastecimiento que permiten la vinculación entre las instituciones de formación y las para ingresar a los estudiantes universitarios de Educación Física en el contexto escolar desde los primeros períodos del curso, una realidad que permite una experiencia educativa en el contexto escolar.

Palabras clave: Formación del Profesorado. la Educación Física. la Escuela. 


\section{INTRODUÇÃO}

O processo de formação de professores em Educação Física passou por uma série de transformações ao longo dos anos, tanto no que diz respeito às bases teóricas quanto à compreensão do que é a sua prática dentro da escola, até porque, uma concepção influencia a outra. As mudanças ocorridas, em especial advindas da reforma curricular impulsionada pelas Diretrizes de Formação de Professores, Resolução CNE/CP 01/2002 e Resolução CNE/ CP 02/2002 (BRASIL, 2002a; BRASIL, 2002b), documentos estes sustentados pelos Pareceres CNE/CP 09/2001, CNE/CP 21/2001, CNE/CP 27/2001 e CNE/CP 28/2001 (BRASIL, 2001a; BRASIL, 2001b; BRASIL, 2001c; BRASIL, 2001d) e a nova resolução do Conselho Nacional de Educação 02/2015, possibilitaram aproximar a Educação Física das demais licenciaturas a partir de uma identidade clara da formação ancorada na docência escolar. Outro aspecto a ser considerado nas mudanças é o fato de exigir dos futuros professores de Educação Física escolar atenção especial na organização didática desta disciplina na escola, mudança essa que contribuirá para sua consolidação na Educação Básica, a exemplo do que já ocorre com os demais componentes curriculares.

Neste sentido, muito se fala em conhecimento didático pedagógico, da sua presença e importância na formação dos futuros professores, algo extremamente necessário e positivo se pensarmos nas atribuições do professor, bem como na qualidade da formação desses futuros profissionais. Mas, quais compreensões e contatos com o local da futura intervenção profissional são oferecidos aos futuros professores de Educação Física no decorrer da formação inicial? Existe preocupação dos professores de Ensino Superior em aproximar os acadêmicos da realidade escolar futura? Ora, se as Diretrizes Curriculares para Formação de Professores apontam como campo de atuação a docência na Educação Básica, nada mais coerente que os cursos de formação de professores de Educação Física levem os graduandos a uma compreensão sobre a instituição escolar, em especial, sobre sua dinâmica de funcionamento e sua cotidianidade.

Diante do exposto, tem-se como objetivo do presente ensaio refletir sobre o lugar da escola na formação dos professores de Educação Física, partindo do princípio de que sem conhecer de fato a escola, o cotidiano escolar, não há possibilidade de compreender suas reais necessidades.

Para tanto, apresentamos a seguir, algumas características históricas, bem como as transformações quanto à formação profissional em Educação Física que ocorreram a fim de adequá-la a escola. Não podemos esquecer, que a gênese da Educação Física brasileira tem suas raízes na escola, a partir da inserção da ginástica nos currículos escolares, ainda na segunda metade do século XIX, mas tal fato parece ser negligenciado na formação dos nossos futuros professores em nome de uma atuação profissional que se corteja mais com o universo das ciências médicas e pouco com a própria pedagogia. Ademais, alguns elementos que fazem parte do cotidiano escolar, a partir de nossas experiências, e que serão apresentados adiante, ainda são pouco discutidas/estudadas nos cursos de formação de professores em Educação Física. 


\section{A Educação Física no Ensino Superior}

Em 1939, a Educação Física passa a condição de um curso de nível superior, com a criação da Escola Nacional de Educação Física e Desporto na Universidade do Brasil, atual Universidade Federal do Rio de Janeiro (BRASIL, 1939). Contudo, isso ocorre sob forte influência militar, tendo seu corpo docente e administrativo formado quase que exclusivamente por militares. Embora a Educação Física fosse um curso de Licenciatura, apresentando como campo de trabalho para seus egressos a escola, seu currículo não possuía disciplinas que contemplassem questões necessárias à formação de professores, como por exemplo, as de cunho pedagógico, conforme destaca Soares (2004).

Essa característica e a demora em adequar os cursos de Educação Física a Lei instituída na época, podem ser justificadas pelos objetivos presentes nos cursos de Educação Física que primavam basicamente pela formação da força física e cultivo de valores morais, em especial o civismo e o patriotismo, distantes dos objetivos de um curso de formação de professores.

Além da proximidade com instituições militares, outra forte e marcante característica dos cursos de Educação Física foi a prática do esporte. Embora presente na Educação Física desde a segunda metade do século XIX no Brasil, foi no final da década de 1960 que os estudiosos da área a identificaram na forma como eles denominam "esportivização da Educação Física", que trouxe novamente mudanças aos currículos dos cursos de Ensino Superior que passaram a formar técnicos em modalidades esportivas e não professores. (BETTI; BETTI, 1996; KOLYNIAK FILHO, 2008).

A valorização do esporte se deu, paulatinamente, nas aulas de Educação Física em meio à herança médico-militar, que ainda se fazia presente nos exames biométricos, nos exercícios severos, nos desfiles e nas demonstrações de ginástica coletiva. (KOLYNIAK FILHO, 2008).

Esse perfil formativo começa a sofrer alterações a partir da publicação da Resolução nº 69/69 que, entre outras mudanças, estabeleceu para os cursos de Educação Física disciplinas pedagógicas como prática de ensino e didática. Ficou estabelecido ainda, que os cursos de Educação Física deveriam ter duração mínima de 3 anos e não 2 anos, como ocorria até aquele momento. Mesmo com essas mudanças o curso mantinha uma formação técnica, portanto, não alterava a compreensão sobre a Educação Física.

Com essa formação de três anos e exclusividade técnica, e com a intervenção quase exclusivamente voltada para o setor educacional, as consequências para a formação do imaginário social sobre a Educação Física e seu profissional acabaram se restringindo a uma visão limitada e pejorativa (OLIVEIRA, 2006, p. 18).

A Educação Física assumia na escola o papel de substituição do pensar pelo exercitar-se, não apresentando nenhuma finalidade pedagógica (OLIVEIRA, 2006).

Souza Neto e colaboradores (2004, p. 120) corroboram a posição de Oliveira (2006), ao afirmarem que: 
[...] os resultados dessa preparação profissional continuam a ser questionados. Os argumentos apresentados para fundamentar a necessidade de se (re)pensar os cursos de licenciatura em educação física foram: a) a necessidade urgente e a importância de os cursos se libertarem das "amarras" impostas pelo currículo mínimo; b) as novas demandas do mercado de trabalho que, já há muito, extrapolavam os limites da escola e, por isso mesmo, reclamava um outro tipo de profissional apto para atender, de forma competente, as necessidades sociais, e c) a importância e necessidade de se pensar a educação física como um campo de conhecimento específico.

Em 1987, com a publicação da Resolução CFE 03/1987 (BRASIL, 1987), uma mudança profunda ocorreu na formação em Educação Física, a possibilidade de escolha entre licenciatura e bacharelado, bem como a ampliação de 3 para 4 anos na formação dos futuros profissionais. Essa resolução apresentou à comunidade acadêmica a possibilidade da iniciação à pesquisa, incluindo a monografia de conclusão de curso, além da abertura de novas áreas de intervenção profissional (OLIVEIRA, 2006).

Souza Neto e colaboradores (2004) destacam que a Resolução CFE 03/1987 (BRASIL, 1987) conferiu flexibilidade a um currículo, segundo os próprios autores, que se apresentava vinculado a um currículo mínimo estabelecido, conferindo as Instituições de Ensino Superior a liberdade para constituição curricular.

No entanto, os próprios autores ressaltam que essa flexibilidade, tanto de oferta de disciplinas como da possibilidade de um curso de licenciatura ou de bacharelado, fez com que muitos currículos propusessem:

[...] uma formação de "dois em um", isso é, mantinha-se "basicamente a mesma estrutura anterior à Resolução n. 3/87 (isto é, uma espécie de licenciatura ampliada), porém, conferindo os dois títulos em formação concomitante" dentro das 2.880 horas (Faria Junior, 1987, p. 4). Como encaminhamento para a solução desses problemas, "num contexto de difícil empregabilidade", propõe-se o resgate da "re-união da formação, conferindo um único título de conclusão - graduação em educação física - apostilando-se a(s) sub-área(s) de aprofundamento de opção do graduando (em função daquelas oferecidas pela IES) (Faria Junior, 1987, p. 5). (SOUZA NETO ET AL., 2004, p. 123).

Após este período de mudanças legais, em 2001, começam a ser debatidas as novas possibilidades de organização da formação de professores de educação básica, culminando com a publicação das Resoluções CNE/CP 01 e 02 de 2002. Importante destacar que estas resoluções se sustentaram em quatro Pareceres CNE/CP 09, 21, 27 e 28 de 2001.

O Parecer CNE 09/2001 aponta para a necessidade de reestruturação dos cursos de formação docente, com vistas a:

fortalecer e aprimorar a capacidade acadêmica e profissional dos docentes formadores; atualizar e aperfeiçoar os formatos de preparação e currículos; dar relevo a docência como base da formação (teoria-prática) atualizar recursos bibliográficos e tecnológicos. (BRASIL, 2001a, p. 4). 
Este Parecer indica ainda três categorias de formação superior: Bacharelado Acadêmico, Bacharelado Profissionalizante e Licenciatura, sendo que a última deve ter currículo próprio, diferente do Bacharelado e da antiga formação de professores. Dessa forma, o processo de Formação Profissional do licenciado, professor, adquire, ou pelo menos deveria adquirir, "ares" específicos de intervenção no ambiente escolar ou como o próprio texto destaca, a educação escolar tem "[...] um papel fundamental no desenvolvimento das pessoas e da sociedade, sendo um dos elementos essenciais para favorecer as transformações sociais necessárias". (BRASIL, 2001a, p. 8).

O documento ressalta que os cursos devem oferecer a possibilidade de articulação entre os conhecimentos básicos e os conhecimentos específicos. Assim, a compreensão do que se deve fazer irá ao encontro das necessidades e interesses particulares/ específicos de cada grupo de alunos, bem como da escola.

A partir do exposto pelo Parecer CNE/CP 09/2001 (BRASIL, 2001a), novo documento é publicado, o Parecer CNE/CP 21/2001 (BRASIL, 2001b), o qual trata da duração e carga horária dos cursos de formação de professores.

Esse parecer aponta conceitos básicos para o entendimento de algumas questões afetas a formação de professores, mas que, de fato, ou sempre foram mal-interpretadas ou interpretadas ao bel-prazer pelos cursos de formação de professores. A mais significativa e que altera a concepção de disposição de carga horária para os cursos diz respeito ao Estágio e a Prática de Ensino, tendo em vista a confusão existente entre estes termos à época.

Moreira (2003) afirma que muitos entendem a Prática de Ensino e o Estágio como sinônimos, dessa forma a conclusão de um implica na conclusão do outro, quando na verdade são ações pertencentes a formação do professor, porém cada qual com suas particularidades.

A Prática de Ensino deve ser realizada "dentro" e no "decorrer" do processo de formação, desde o primeiro ano de curso, enquanto o Estágio fica caracterizado como uma prática realizada fora da Instituição, em contato com a realidade, sob a supervisão de um professor devidamente habilitado.

Entende-se assim, que o presente parecer é extremamente esclarecedor, não deixando margem para qualquer mal entendido, exigindo que as Instituições cumpram suas obrigações, o que poderá melhorar sensivelmente a formação do professor.

Assim, os cursos devem adotar um currículo com no mínimo 2800 horas subdivididas em:

- 400 (quatrocentas) horas de prática de ensino, vivenciadas ao longo do curso;

- 400 (quatrocentas) horas de estágio supervisionado, sob forma concentrada ao final do curso;

- 1800 (mil e oitocentas) horas para os conteúdos curriculares de atividades acadêmico-científico-culturais em sala de aula;

- 200 (duzentas) horas para outras formas de atividades acadêmico-científico-culturais. Art. $2^{\circ}$ : A duração da carga horária prevista no Art. $1^{\circ}$ desta Resolução, obedecidos os 200 (duzentos) dias letivos-ano dispostos na LDB, será integralizada em, no mínimo, 3 (três) anos letivos. (BRASIL, 2001b, p. 16). 
Portanto, o curso deve buscar relações constantes entre práticas pedagógicas no "seio" de cada disciplina, bem como se articular com a realidade, oferecendo uma característica dinâmica ao processo de formação docente.

Vale destacar que, um ajuste foi necessário a este parecer, tendo em vista o texto apresentado pelo inciso IV do Art. 1º: "400 (quatrocentas) horas de estágio supervisionado, sob forma concentrada ao final do curso;". (BRASIL, 2001b, p. 16). O que por sua vez acarretou a elaboração do Parecer CNE/ CP 27/2001 (BRASIL, 2001c).

O Parecer CNE/ CP 27/2001 teve por finalidade efetuar uma correção ao texto publicado no Parecer CNE/ CP 21/2001 (BRASIL, 2001b), que afirmava que os estágios deveriam ser realizados apenas no final do curso, que de certa forma inviabilizava a relação dos conhecimentos obtidos durante o processo formativo com a realidade futura.

Assim, resolve:

Deve, de acordo com o projeto pedagógico próprio, se desenvolver a partir do início da segunda metade do curso, reservando-se um período final para a docência compartilhada, sob a supervisão da escola de formação, preferencialmente na condição de assistente de professores experientes. (BRASIL, 2001c, p. 1).

Isto posto, cabe as Instituições de Ensino Superior organizar as atividades de Estágio de seus alunos de forma a oportunizar espaços para construção dos saberes práticos, oriundos da observação, participação e regência das atividades e compreender a Prática de Ensino como um espaço de formação e construção coletiva.

Por sua vez, o Parecer CNE/ CP 28/2001 (BRASIL, 2001d) ofereceu nova redação ao Parecer CNE/ CP 21/2001, tendo em vista, manter a coerência com outras disposições governamentais. Dessa forma, a Assessoria Técnica da Coordenação de Formação de Professores SESu/ MEC emitiu um parecer, para que assim, houvesse consonância entre o proposto e as disposições existentes.

A alteração que ocorreu destaca que a Prática de Ensino como componente curricular deve ser desenvolvida na reflexão sobre as ações profissionais e durante as atividades profissionais, oferecendo um entendimento que não estava latente no Parecer CNE/ CP 21/2001 (BRASIL, 2001b).

"Assim, há que se distinguir, de um lado, a prática como componente curricular e, de outro, a prática de ensino e o estágio obrigatório definidos em lei. A primeira é mais abrangente: contempla os dispositivos legais e vai além deles". (BRASIL, 2001d, p. 9).

Após o período de debate e nova organização da formação em nível superior de professores, que por sua vez, alterou a formação no campo da Educação Física, em 2015, a Resolução CNE/CP 02 de 2015 (BRASIL, 2015), ratifica o contexto educacional e, por conseguinte a escola, em seu artigo $7^{\circ}$, como um espaço formativo, ao definir que os acadêmicos dos cursos de formação de professores devem ser conduzidos a:

I - estudo do contexto educacional, envolvendo ações nos diferentes espaços escolares, como salas de aula, laboratórios, bibliotecas, espaços recreativos e desportivos, ateliês, secretarias; [...] 
IV - participação nas atividades de planejamento e no projeto pedagógico da escola, bem como participação nas reuniões pedagógicas e órgãos colegiados; [...]

VII - cotejamento e análise de conteúdos que balizam e fundamentam as diretrizes curriculares para a educação básica, bem como de conhecimentos específicos e pedagógicos, concepções e dinâmicas didático-pedagógicas, articuladas à prática e à experiência dos professores das escolas de educação básica, seus saberes sobre a escola e sobre a mediação didática dos conteúdos; [...]

Frente ao exposto, entendemos que a formação de professores em Educação Física apresenta orientações claras, no contexto atual, sobre como deve se dar. Não obstante, devemos considerar que uma boa formação profissional conduzirá professores a buscar novas orientações e estudos para sua prática pedagógica, o que entendemos, poderá despertar o interesse em pesquisar e produzir novos conhecimentos.

O estudo de Nascimento (2010) revela que das 333 teses de doutorado em Educação Física apresentadas entre os anos de 1994 e 2008, apenas 16 tiveram como tema a Educação Física escolar. Para o autor isso demonstra a falta de interesse e investimento na pesquisa em Educação Física escolar, que poderia ser uma forma de aproximação dos professores que atuam no Ensino Superior com o âmbito escolar, e ressaltam a urgência de repensar essa situação para que as conquistas no campo pedagógico e legal não se percam.

Esse estudo reforça a ideia de que sem aproximação do cotidiano escolar, o professor de Ensino Superior falará do que imagina ser e não do que é, sem pesquisas que se interessem pela docência na escola, sejam mestrados ou doutorados que estudem a questão, sem projetos de ensino, de pesquisa e de extensão, sem programas de iniciação à docência, como é o caso do PIBID - Programa Institucional de Bolsa de Iniciação à Docência, sem a utilização da Prática como Componente Curricular e do Estágio como elementos centrais nos cursos de formação, não será possível avançar.

Sendo assim, os números e as ponderações de Betti, Ferraz e Dantas (2011) reforçam nossa ideia inicial sobre a necessidade de estudos mais aprofundados sobre a escola em si e não apenas das questões pedagógicas dentro dos cursos de Licenciatura em Educação Física.

O que os autores apontam faz sentido, visto que os mesmos identificaram que uma pequena parcela dos periódicos da área 21 apresenta espaço para a subárea Educação Física escolar, além da biodinâmica e sociocultural. Quanto à classificação dos textos, apenas 21,02\% foram considerados pelos autores como "Educação Física Escolar", mesmo sendo raras as instituições que não oferecem o curso de Educação Física na modalidade Licenciatura. Ainda sobre a classificação dos textos, foram considerados Educação Física escolar os que estabeleciam algum tipo de relação com o contexto social escolar dos alunos.

Assim, parece-nos que a Educação Física permanece no limbo identificado por González e Fensterseifer (2010) "entre o não mais e o ainda não", ou seja, problemas, fragilidades e soluções parecem ter sido identificados, mas as transformações ainda não aconteceram de fato.

A partir do exposto, entendemos que se faz necessário encontrar o lugar da escola na formação dos futuros professores de Educação Física. 


\section{A escola, o cotidiano escolar: e a Educação Física?}

De acordo com Gómez (1998), a aceleração do desenvolvimento da sociedade trouxe novas demandas ao processo de socialização das pessoas, fazendo com que surgisse o sistema de escolarização obrigatório que temos na sociedade contemporânea. Autores e correntes da sociologia da educação concordam que são dois os objetivos básicos da socialização dos alunos na escola: a preparação para incorporação ao mundo do trabalho e a formação cidadã para intervir na vida pública, mantendo assim, a dinâmica, o equilíbrio e as normas de convivência nas instituições sociais.

Embora, aparentemente, a escola apresente um papel social claro e muito bem definido, ao adentrar esse campo percebemos o quão complexo e conflituoso na verdade ele é. A exemplo disto estão as contradições entre aquilo que se chama "direito" e a esfera "econômica" na qual, por um lado a escola tem o dever de despertar o senso crítico do aluno de modo que este intervenha na realidade social, por outro lado precisa fazer deste aluno, submisso e disciplinado, atendendo assim as necessidades do mercado de trabalho, conforme destaca Gómez (1998).

Além das questões sociais, filosóficas e ideológicas que movimentam a escola, existem também as leis, a cultura e a forma de organização, que pode variar de uma escola para a outra, dependendo do nível de ensino, das necessidades e da realidade em que está inserida.

Com relação a legislação, sabemos que estão envolvidas as esferas federal, estadual e municipal, cada uma com suas responsabilidades, de acordo com o nível de ensino e que são essas leis que determinam. Por exemplo, a destinação de verba para a educação com a qual são realizados desde pequenos reparos, compra de material pedagógico, até as grandes obras como a construção ou reformas de unidades escolares. (BRASIL, 1988; BRASIL, 1996).

Sobre a cultura e a forma de organização da escola, são muito particulares em determinadas situações, mas, fundamentalmente, influenciam muito a prática pedagógica dos professores, pois é com base nelas que as temáticas, bem como as atividades que serão desenvolvidas durante todo o período letivo são pensadas, e isso envolve também conhecer a comunidade escolar. Entendemos, portanto, que a ação pedagógica dos professores não pode ocorrer de forma isolada, sem a participação e envolvimento de outros docentes. $\mathrm{O}$ trabalho deve acontecer de modo que cada área do conhecimento dê, por meio de seus professores, a sua contribuição no processo ensino-aprendizagem, e isso vale também para o professor de Educação Física.

Para que isto tenha maiores possibilidades de se tornar realidade, os conhecimentos básicos sobre a escola precisam estar claros para os professores que atuam no Ensino Superior, tornando-se parte da formação de professores em Educação Física, independentemente da disciplina que ministre no curso, pois se falamos de um curso de Licenciatura, tratamos da formação de profissionais que, em primeira instância, terão a escola como campo de atuação. Caso contrário, os futuros professores somente terão como oportunidade de aprendizagem, a própria atuação, o que compromete a qualidade do trabalho, bem como 
o dificulta. Nesse sentido, deve-se fortalecer os momentos de formação dentro da escola, em especial nos Estágios Curriculares obrigatórios, o planejamento e execução de trabalhos acadêmicos nas diferentes disciplinas do curso que levam os graduandos para o espaço escolar e, principalmente, ampliar a participação dos graduandos no PIBID - Programa Institucional de Bolsa de Iniciação à Docência.

Dessa forma, a formação dos professores deve conceber:

Em primeiro lugar, a ideia da escola como o lugar da formação dos professores, como o espaço da análise partilhada das práticas, enquanto rotina sistemática de acompanhamento, de supervisão e de reflexão sobre o trabalho docente. O objectivo é transformar a experiência colectiva em conhecimento profissional e ligar a formação de professores ao desenvolvimento de projectos educativos nas escolas. Em segundo lugar, a ideia da docência como colectivo, não só no plano do conhecimento mas também no plano da ética. Não há respostas feitas para o conjunto de dilemas que os professores são chamados a resolver numa escola marcada pela diferença cultural e pelo conflito de valores. Por isso, é tão importante assumir uma ética profissional que se constrói no diálogo com os outros colegas.

A colegialidade, a partilha e as culturas colaborativas não se impõem por via administrativa ou por decisão superior. A formação de professores é essencial para consolidar parcerias no interior e no exterior do mundo profissional. (sic.). (NÓVOA, 2009, p. 41)

Diante disso, como despertar o pensamento crítico dos alunos sem transformar a prática e a realidade da Educação Física dentro das escolas?

Ao considerarmos o papel social do processo de escolarização, mesmo diante dos conflitos e contradições, o objetivo de um curso de Licenciatura deveria ser de formar professores que atuarão na Educação Básica sendo capazes de proporcionar aos alunos experiências com base nos principais objetivos deste processo, ou seja, uma formação que permita ao sujeito ser pensado e pensar plenamente.

Dessa forma, um curso de Licenciatura deve constituir-se, das especificidades de cada área do conhecimento, do conhecimento do cotidiano escolar, das necessidades específicas de cada nível de ensino da Educação Básica nas dimensões cultural, social, política, econômica, de modo que contemple todo o desenvolvimento humano e não apenas as questões técnicas de uma determinada área.

Sendo assim, "a prática educativa requer uma direção de sentido para a formação humana dos indivíduos e processos que assegurem a atividade prática que lhes corresponde" (LIBÂNEO, 2001, p. 24). Com isso, os egressos dos cursos de Licenciatura receberão não a garantia de uma atuação sem falhas, mas a oportunidade de perceber qual o seu verdadeiro papel dentro da escola como mediador no processo de aprendizagem do aluno, levando-o a atingir os objetivos que a escola estabeleceu de acordo com a realidade de cada comunidade escolar.

Sendo assim, os objetivos do ensino de um componente curricular serão atingidos quando estiverem associados aos objetivos de ensino e da aprendizagem da escola, numa ação organizada, dirigida e desenvolvida coletivamente. 
Nesse sentido, Neira (2009) destaca que os objetivos da Educação Física escolar são os mesmos que os da escola, cabendo, não somente a ela, mas a todos os componentes curriculares estudar e aprofundar uma parcela determinada da cultura, no caso específico da Educação Física, o patrimônio corporal, investigando como grupos sociais se apropriam de movimentos, como criam e podem criar novos esportes, jogos, lutas, ginásticas, brincadeiras, danças, ou ainda, como a escola pode transformar essas criações.

É neste sentido que falamos de uma ação pedagógica conjunta e não isolada, tendo o professor de Educação Física a mesma responsabilidade que os demais, tratando de assuntos, por exemplo, transversais, definidos pela escola, apresentando as contribuições da área para a escola e os alunos, de uma forma geral.

Outra questão importante é a oportunidade de intervir/ contribuir na escola tanto quanto os demais professores, no sentido de participar das reuniões pedagógicas, administrativas e de pais, compreender a função do conselho escolar comunitário e participar dele também. Saber, por exemplo, que existem programas do Governo Federal que financiam a compra de materiais e que esses projetos são elaborados por equipes organizadas dentro da unidade escolar que contam com a participação de professores, dentre tantas outras situações que permeiam o cotidiano escolar e, portanto, fazem parte da atuação do professor.

O trabalho do professor na Educação Básica não está restrito a sala de aula/ quadra, ao contato com os alunos. A ele, somam-se ainda questões políticas, econômicas, administrativas que não podem esperar o início da atuação para se tornarem parte do conhecimento dos professores, pois a escola não é um local neutro, sem interesses, sem brigas por espaços. Nesse contexto, a falta de conhecimento sobre aquilo que acontece dentro da escola, torna o trabalho do professor ainda mais complexo.

A prática do professor de Educação Física dentro da escola sempre foi interpretada como desprovida de caráter pedagógico formativo, considerando-se que a ação do professor de Educação Física esteve, na maioria das vezes, centrada nos aspectos procedimentais em detrimento das dimensões conceituais e atitudinais dos conteúdos. Não é à toa que os professores dos demais componentes curriculares e coordenadores pedagógicos da escola estão acostumados a ver a Educação Física desta forma e é daí que vem a necessidade dos cursos de Licenciatura mostrarem aos futuros professores que a integração com outras áreas do conhecimento pode acontecer.

O diálogo com os outros componentes curriculares é um fator essencial para o estabelecimento de uma relação curricular que pode possibilitar, em primeira instância, uma articulação pedagógica, principalmente nas reuniões pedagógicas, capaz de favorecer adequada organização didática de todos os componentes do currículo escolar. É neste momento que os professores podem tirar suas dúvidas, compartilhar anseios e dividir ideias.

Nesta perspectiva, Tardif (2002) alerta sobre as dificuldades que o professor enfrenta ao iniciar sua atuação, entre elas está a relação com os demais profissionais que atuam na escola, embora o autor não trate especificamente das dificuldades do professor de Educação Física. Em muitas situações pode não haver interesse por parte das pessoas que estão há mais tempo na unidade escolar em auxiliar aqueles que estão chegando. Se, durante a 
graduação, o professor não tiver acesso à rotina da escola e auxílio de quem está a mais tempo nesta, como chegarão a ele essas informações?

Ao discutir tal aspecto Pimenta e Anastasiou (2002) mencionam quão complexa e particular é a atuação do professor:

A profissão professor exige de seus profissionais alteração, flexibilidade, imprevisibilidade. Não há modelos ou experiências modelares a serem aplicadas. A experiência acumulada serve apenas de referência, nunca de padrão de ações com segurança de sucesso. Assim, o processo de reflexão, tanto individual como coletivo, é a base para a sistematização de princípios norteadores de possíveis ações, e nunca de modelos. (PIMENTA; ANASTASIOU, 2002, p. 199).

A afirmação supracitada apresenta-se pertinente ao presente texto, pois sabemos que a escola tem autonomia para tomar decisões em diversas situações, o que pode modificar sua rotina e organização de acordo com o local onde está inserida, de sua esfera administrativa, se pública ou privada, mas conhecer a diversidade do cotidiano escolar se traduz em experiência que pode estar presente na atuação do professor desde o início de sua carreira se esta possibilidade, é claro, fizer parte do processo de formação.

Por isso, a importância e necessidade do professor que atua no Ensino Superior em se aproximar e/ ou vivenciar a rotina escolar, uma vez que nem tudo que está no papel se realiza de fato e nem tudo que se realiza está no papel.

\section{CONSIDERAÇÕES FINAIS: A FORMAÇÃO DE PROFESSORES DE EDUCAÇÃO FÍSICA E COTIDIANIDADE, MAS ENTÃO, O QUE PODEMOS FAZER?}

Durante muito tempo os cursos de formação de professores em Educação Física estiveram pautados apenas em questões técnicas, fato que passou a ser questionado, uma vez que os profissionais formados sob esta égide tinham como campo de atuação a escola. Os estudiosos começaram a entender que as exigências para a atuação neste local eram outras e as disciplinas de cunho pedagógico começaram a ser introduzidas nos currículos de tais cursos.

No entanto, considerando a própria formação dos formadores, citada anteriormente, sem foco específico na Educação Física escolar e na docência para a Educação Básica, a formação mais voltada para produção intelectual, o baixo status social que o "ser professor" adquiriu, a lógica e a influência da mídia nos hábitos de vida da população, dentre outros aspectos, alteraram o foco da formação nesses cursos e o esporte e a saúde passaram a ser enfatizados, prevalecendo o caráter técnico. É importante esclarecer que, não há nada contra a prática esportiva e a ideia de que a prática de atividade física traz benefícios à saúde, o que se questiona é o local e a forma como vem sendo abordadas.

Pois bem, muito tempo já se passou desde o início dessas discussões, mas elas ainda continuam atuais, por isso nosso questionamento sobre o lugar da escola dentro dos cursos de Licenciatura em Educação Física, uma vez que na forma como se encontra, a Educação 
Física ainda se apresenta como algo a ser inserido dentro da escola e não como parte dela. Realidade que exige de todos, em especial dos agentes formadores, investimento acadêmico que mostre, desde o início do curso, que é necessário consolidar a Educação Física como componente curricular na Educação Básica, bem como torna-se premente a adoção de uma organização curricular que se aproxime da organização dos demais componentes curriculares para que a Educação Física tenha melhor status no currículo escolar além de tornar seus objetivos mais adequados à escola, distanciando-se das premissas técnicas.

Os cursos de formação de professores em Educação Física precisam apropriar-se daquilo que acontece dentro da escola com o intuito de mostrar aos futuros professores qual será a participação deles no cotidiano escolar, o que inclui além das questões didáticas e pedagógicas, as administrativas, políticas, sociais e filosóficas, uma vez que estão interligadas e influenciam diretamente o trabalho do professor.

A relação da formação de professores em Educação Física com o cotidiano escolar deve permear todas as disciplinas da matriz curricular do curso, ou seja, deve ser do conhecimento de todos os professores que ministram aulas em tais cursos e não apenas daqueles que, teoricamente estão mais próximos da escola, os que são responsáveis pelos estágios, como se apresenta na Resolução CNE/CP 01 de 2002, reforçada pela Resolução CNE/CP 15/2015, por exemplo.

Importante destacar que esta relação deve ser contínua, tendo em vista as constantes transformações pelas quais a escola passa. A escola de 10 anos atrás não é mais a escola dos dias atuais. O aluno de 10 anos atrás não é mais o aluno dos dias atuais. Portanto, as exigências para atuação do professor também são outras. Não podemos continuar pensando que as concepções de Educação Física de anos atrás suprirão as necessidades da escola dos dias atuais, assim as Práticas como Componente Curricular assumem papel de destaque no cenário da formação, conforme pontuam diversos autores (CARDOSO ET AL., 2014; SOUZA NETO; SILVA, 2014; MARCON; NASCIMENTO; GRAÇA, 2007; MARCON; NASCIMENTO; GRAÇA, 2012).

Outro ponto importante é o conhecimento e a participação ativa do professor de Educação Física em programas que podem trazer recursos financeiros para a escola, daí a importância de disciplinas que abordem a gestão pública, a administração escolar e organização escolar, dentre outras, oferecendo ao professor a oportunidade de mostrar a necessidade e solicitar a compra de materiais para as suas aulas, o que traz, não apenas melhores experiências para os alunos, mas também, melhores condições de trabalho para os professores e inúmeras possibilidades formativas para os futuros professores de Educação Física.

No contexto atual, a escola está em constante transformação, configurando-se como um espaço para inclusão de projetos e programas que, além de favorecer a melhoria do seu funcionamento, também possibilita espaços formativos e de intervenções. É assim que o Programa Mais Educação e o próprio PIBID têm contribuído significativamente para a inserção dos licenciandos nas escolas, os quais têm oportunidade de vivenciar o universo escolar já nos primeiros momentos do curso e isto, sem dúvidas, vai contribuir na compreensão que o mesmo deve ter sobre a escola. 
Os futuros professores, durante o processo de formação, deveriam ainda, vivenciar as reuniões pedagógicas do início do ano letivo onde o projeto político pedagógico é, geralmente, revisado e/ ou readequado, momento oportuno para discutir coletivamente o planejamento de ensino anual, além das reuniões com os pais, as reuniões do conselho escolar comunitário, dentre outras atividades que fazem parte da rotina de um professor. A implementação do conselho escolar comunitário nas escolas, por exemplo, aparece somente na década de 1990, fruto das discussões da LDB - Lei de Diretrizes e Bases (BRASIL, 1996) e, todos sabem o quanto esses processos são lentos. Portanto, se os professores que atuam no Ensino Superior não mantiverem contato com a escola como saberão de fato como os conselhos escolares comunitários estão sendo organizados?

Composto por representantes da escola, pais e, dependendo do nível de ensino, por alunos, o conselho escolar comunitário, pode ser um grande aliado do professor de Educação Física, pois todas as decisões tomadas dentro da escola precisam passar por ele. Se o professor sai da graduação com esse conhecimento, ao chegar na escola e identificar uma situação que dificulta seu trabalho e que se arrastando por certo período sem que a equipe gestora tome providências, o conselho escolar comunitário poderá auxiliá-lo.

Estes aspectos sugerem que não apenas as aulas nas disciplinas de estágio supervisionado permitam o contato com os alunos e com o ser professor, mas também um acompanhamento das atividades escolares que acontecem fora da sala de aula, conforme destacamos anteriormente (BRASIL, 2001a; 2001b; 2001c; 2001d; 2002a; 2002b; 2015). Neste sentido, o tempo da escola deve ser considerado e não o tempo das universidades, pois quem faz a escola não são os professores, ou as correntes de pensamento da sociologia e filosofia da educação, ou um ponto de vista sobre uma determinada situação, mas sim a sociedade com todas as suas contradições e mudanças.

A relação estabelecida na Educação Física com o movimento humano torna esse aspecto ainda mais perceptível, pois alguns de seus professores ainda insistem em privilegiar performances, e não diferentemente de outros cursos, preferem as exposições de conteúdo aos debates e discussões.

Apenas conhecendo a escola e seu cotidiano de forma aprofundada a Educação Física poderá se tornar parte desta, como entendemos que de fato deva e possa ser. Com isto, será possível perceber que algumas questões que permeiam a história da Educação Física não podem mais ser mantidas, pelo menos não dentro da escola.

Sendo assim, por mais que novas temáticas se façam presentes e necessárias nos dias atuais, as questões relacionadas à formação e atuação dos professores não devem ser esquecidas, pois é a partir delas que a Educação Física se mostra como de fato ela é.

\section{REFERÊNCIAS}

BETTI, Irene Conceição Andrade Rangel; BETTI, Mauro. Novas perspectivas na formação profissional em Educação Física. Motriz, v. 2, n. 1, p. 10-15, jun.1996. 
BETTI, Mauro; FERRAZ, Osvaldo Luiz; DANTAS, Luiz Eduardo Pinto Basto Tourinho. Educação física escolar: estado da arte e direções futuras. Revista brasileira de educação física e esporte, v. 25, n. especial, p. 105-115, dez. 2011.

BORGES, Cecília Maria Ferreira. O professor de educação física e a construção do saber.

Campinas, SP: Papirus, 1998.

BRASIL. Decreto-Lei no 1.212, de 17 de Abril de 1939. Cria, na Universidade do Brasil, a Escola Nacional de Educação Física e Desportos. Diário oficial [da] República Federativa do Brasil. Brasília, DF, 20 abr. 1939. Seção I, p. 9073.

. Resolução CFE 69, de 06 de novembro de 1969. Fixa os mínimos de conteúdo e duração a serem observados na organização dos Cursos de Educação Física. Brasília, DF, 06 nov. 1969.

. Resolução CFE 3, de 16 de junho de 1987. Fixa os mínimos de conteúdos e duração a serem observados nos cursos de graduação em Educação Física (Bacharelado e/ ou Licenciatura Plena). Diário Oficial [da] República Federativa do Brasil, Poder Executivo, Brasília, DF, 22 jun. 1987. Seção I, p. 9635-9636.

. Constituição da República Federativa do Brasil. Diário oficial [da] República

Federativa do Brasil. Poder Executivo, Brasília, DF, 05 out. 1988.

. Lei no 9.394, de 20 de dezembro de 1996. Estabelece as Diretrizes e bases da

Educação Nacional. Diário oficial [da] República Federativa do Brasil. Poder Executivo, Brasília, DF, 23 dez. 1996.

. Conselho Nacional de Educação. Parecer 009/2001: Diretrizes Curriculares Nacionais para a Formação de Professores da Educação Básica, em nível superior, curso de licenciatura, de graduação plena. Brasília, DF, 2001a.

. Conselho Nacional de Educação. Parecer 021/2001: Duração e carga horária dos cursos de Formação de Professores da Educação Básica, em nível superior, curso de licenciatura, de graduação plena. Brasília, DF, 2001b.

. Conselho Nacional de Educação. Parecer 027/2001: Dá nova redação ao item 3.6, alínea c, do Parecer CNE/CP 9/2001, que dispõe sobre as Diretrizes Curriculares Nacionais para a Formação de Professores da Educação Básica, em nível superior, curso de licenciatura, de graduação plena. Brasília, DF, 2001c.

. Conselho Nacional de Educação. Parecer 028/2001: Dá nova redação ao Parecer CNE/CP 21/2001, que estabelece a duração e a carga horária dos cursos de Formação de Professores da Educação Básica, em nível superior, curso de licenciatura, de graduação plena. Brasília, DF, 2001d.

. Resolução CNE/CP 1, de 18 de fevereiro de 2002. Institui Diretrizes Curriculares Nacionais para a Formação de Professores da Educação Básica, em nível superior, curso de licenciatura, de graduação plena. Diário Oficial [da] República Federativa do Brasil, Poder Executivo, Brasília, DF, 4 mar. 2002a. Seção I, p. 9.

. Resolução CNE/CP 2, de 19 de fevereiro de 2002. Institui a duração e carga horária dos cursos de licenciatura, de graduação plena, de formação de professores da Educação Básica em nível superior. Diário Oficial [da] República Federativa do Brasil, Poder Executivo, Brasília, DF, 4 mar. 2002b. Seção I, p. 8. 
. Resolução CNE/CP 2, de $1^{\circ}$ de julho de 2015. Define as Diretrizes Curriculares Nacionais para a formação inicial em nível superior (cursos de licenciatura, cursos de formação pedagógica para graduados e cursos de segunda licenciatura) e para a formação continuada. Diário Oficial [da] República Federativa do Brasil, Poder Executivo, Brasília, DF, 2 jul. 2015. Seção I, p. 8-12.

. Decreto $n^{\circ} 7219$, de 24 de junho de 2010. Dispõe sobre o Programa Institucional de Bolsa de Iniciação à Docência - PIBID e dá outras providências. Diário oficial [da] República Federativa do Brasil. Poder Executivo, Brasília, DF, 25 jun. 2010.

CARDOSO, Viviani Dias Cardoso e colaboradores. A prática como componente curricular na formação inicial em educação física: um estudo com professores no início da carreira. Anais ANPED SUL, 10, Florianópolis, SC, 2014.

GÓMEZ, Ángel Ignácio Pérez. As funções sociais da escola: da reprodução à reconstrução crítica do conhecimento e da experiência. In. GÓMEZ, Ángel Ignácio Pérez; SACRISTÁN, José Gimeno. Compreender e transformar o ensino. 4. ed. Porto Alegre, RS: Artmed, 1998.

GONZÁLEZ, Fernando Jaime; FENSTERSEIFER, Paulo Evaldo. Entre o "não mais" e o "ainda não": pensando saídas do não lugar da educação física escolar II. Cadernos de Formação RBCE, 2010; v. 1, n. 2, p. 10-21, mar. 2010.

KOLINIAK FILHO, Carol. Educação física: uma (nova) introdução. 2 ed. São Paulo: EDUC, 2008.

LIBÂNEO, José Carlos. Didática. São Paulo: Cortez, 2001.

MARCON, Daniel; NASCIMENTO, Juarez Vieira do; GRACA, Amândio Braga dos Santos. A construção das competências pedagógicas através da prática como componente curricular na formação inicial em Educação Física. Revista Brasileira de Educação Física e Esporte, São Paulo, SP, v. 21, n. 1, p. 11-25, 2007.

MARCON, Daniel; NASCIMENTO, Juarez Vieira do; GRACA, Amândio Braga dos Santos. Desenvolvimento das competências pedagógicas nas práticas como componente curricular das disciplinas esportivas na formação inicial em Educação Física. In: FARIAS, Gelcemar Oliveira; FOLLE, Alexandra; BOTH, Jorge (Orgs.). Educação física: formação e regulamentação profissional. Chapecó, SC: Argos, 2012, v. 1, p. 55-76.

MOREIRA, Evando Carlos. Formação de professores de educação física: a importância da prática de ensino e do estágio supervisionado na construção dos saberes práticos. Corpoconsciência, Santo André, SP, v. 7, n. 11, p. 31-48, jan.-jun., 2003.

NASCIMENTO, Ana Claudia Silvério. Mapeamento temático das teses defendidas nos programas de pós-graduação em educação física no Brasil (1994-2008). 2010. 278 f. Tese (Doutorado em Ciência da Informação) - Escola de Comunicação e Artes, Universidade de São Paulo, São Paulo, 2010.

NEIRA, Marcos Garcia. Educação física na educação infantil: algumas considerações para elaboração de um currículo coerente com a escola democrática. In: ANDRADE FILHO, Nelson Figueiredo; SCHNEIDER, Omar. (Orgs.). Educação física para a educação infantil: conhecimento e especialidade. São Cristóvão, SE: UFS, 2008. 
NEIRA, Marcos Garcia. Em vez de formar atletas, analisar a cultura corporal. Nova Escola, 2009; n. 224, p. 38-42, ago. 2009.

NÓVOA, Antonio. Professores: imagens do futuro presente. Lisboa, Portugal: Educa, 2009. OLIVEIRA, Amauri Aparecido Bássoli de. A formação profissional em educação física: legislação, limites e possibilidades. In: SOUZA NETO, Samuel de; HUNGER, Dagmar Aparecida Cynthia França. (Orgs.). Formação profissional em educação física: estudos e pesquisas. Rio Claro, SP: Biblioética, 2006, p. 17-32.

PIMENTA, Selma Garrido; ANASTASIOU, Léa das Graças Camargos. Docência no Ensino Superior. São Paulo: Cortez, 2002.

SOARES, Carmen Lúcia. Educação física: raízes européias e Brasil. 3. ed. Campinas, SP: Autores Associados, 2004.

SOUZA NETO, Samuel de e colaboradores. A formação do profissional de educação física no Brasil: uma história sob a perspectiva da legislação federal no século XX. Revista Brasileira de Ciências do Esporte, Campinas, SP, v. 25, n. 2, p. 350-362, jan., 2004.

SOUZA NETO, Samuel de; SILVA, Vandeí Pinto da. Prática como componente curricular: questões e reflexões. Revista Diálogo Educacional, Curitiba, PR, v. 14, n. 43, p. 889909, 2014.

TARDIF, Maurice. Saberes docentes e formação profissional. Petrópolis, RJ: Vozes, 2002.

Recebido em: maio/2016 Aprovado em: outubro/2016 